\title{
DETERMINAÇÃO DA MASSA ESPECÍFICA DE BIOMASSA DE PLANTAS DO NORDESTE DO BRASIL E SEUS BIOCARVÕES E AVALIAÇÃO DA AFINIDADE METÁLICA PARA OS ÍONS $\mathrm{Cu}^{+2}$, $\mathrm{Ni}^{+2}$ e $\mathrm{Cr}^{+3}$
}

\author{
S. C. M. SIGNORELLI ${ }^{1}$, T. L. SILVA ${ }^{1}$, K. J. L. SANTOS ${ }^{2}$, J. I. $\operatorname{SOLETTI}^{2}$, M. G. A. \\ VIEIRA $^{1}$ \\ ${ }^{1}$ Universidade Estadual de Campinas, Faculdade de Engenharia Química \\ ${ }^{2}$ Universidade Federal de Alagoas, Centro de Tecnologia - CTEC \\ E-mail para contato: melissagav@ feq.unicamp.br
}

\begin{abstract}
RESUMO - O objetivo desse trabalho foi determinar a massa específica de biomassa e carvões produzidos a partir de material celulósico de palmeiras nativas da região nordeste do Brasil e avaliar a afinidade desses materiais por metais tóxicos cobre, níquel e cromo. Utilizou-se material in natura, casca e endocarpo dos frutos das palmeiras, que é a casca mais dura descartada do aproveitamento da polpa e das amêndoas. Os resultados indicaram que os carvões possuem massa específica entre 1,3992 e 2,1986 g. $\mathrm{cm}^{-3}$. Os testes de afinidade metálica indicaram que o processo de pirólise não foi capaz de produzir biocarvões com capacidade de serem utilizados em processos de adsorção de metais tóxicos, devido às baixas remoções observadas, sendo necessária a implementação de técnicas de ativação conjuntas a carbonização da biomassa.
\end{abstract}

\section{INTRODUÇÃO}

O aumento da atividade industrial resulta, consequentemente, no crescimento na quantidade de resíduos industriais gerados. Dentre eles podemos destacar os efluentes líquidos que são originados em processos industriais, lavagens de máquinas, tubulações e pisos, águas de sistemas de resfriamento e geradores a vapor; esgotos sanitários, dentre outros (Giordano, 2007).

Dentre os poluentes, os metais tóxicos são a classe mais importante devido sua toxicidade que implica em severos riscos à saúde pública. $\mathrm{Na}$ forma iônica, solúvel em meio aquoso, os metais são estáveis e persistentes, possuindo grande mobilidade no ecossistema, além de apresentar capacidade de se bioacumular em seres vivos (Demirbas, 2008). No Brasil, o CONAMA - Conselho Nacional do Meio Ambiente é o órgão governamental que regulamenta por meio das resoluções $n^{\circ} 430$ e $n^{\circ} 357$, os padrões de lançamento de efluentes líquidos contaminados.

Dentre os métodos utilizados para o tratamento de efluentes contendo metais tóxicos a adsorção se destaca devido sua capacidade de remover esses poluentes mesmo em baixas concentrações (Wang e Chen, 2006). Em função do alto custo de carvões ativados tradicionais pesquisas têm se dedicado a investigar a utilização de matérias-primas alternativas para a 
produção de carvão, tanto para fins energéticos, quanto para a produção de materiais adsorventes.

A termoconversão de biomassa em carvão é influenciada pela reatividade do material adquirida na fase de pirólise, que é a degradação térmica do material orgânico em ambiente com pouco oxigênio (Wang et al., 2013; Tsamba et al., 2006). A utilização dos biocarvões depende de suas propriedades físico-químicas, como grande área superficial, que indica seu potencial como adsorvente de contaminantes. A matéria-prima é um fator crítico e os biocarvões podem ser gerados a partir de uma grande variedade de materiais. Dentre as biomassas utilizadas na produção de biocarvões incluem-se madeiras e seus resíduos, resíduos agrícolas, como, palha, casca de arroz, cascas de noz, endocarpo dos frutos das palmeiras, resíduos agropecuários, lodo de esgotos, dentre outros (Wang et al., 2013, Tsamba et al., 2006). Dentre esses materiais, as cascas de coco (endocarpo) de diversas palmeiras bem como suas fibras, são abundantes em países da América Latina, África e Ásia, sendo resíduos de diferentes processos agroindustriais (Tsamba et al., 2006).

O objetivo desta etapa do estudo foi caracterizar quanto à massa específica tanto a biomassa proveniente de plantas nativas da região nordeste do Brasil - Rabo-de-raposa e Catolé - e quanto os carvões produzidos em diferentes temperaturas de pirólise dessas plantas, além de avaliar a afinidade metálica dos biomateriais e biocarvões pelos metais tóxicos cobre $\left(\mathrm{Cu}^{2+}\right)$, níquel $\left(\mathrm{Ni}^{2+}\right)$ e cromo trivalente $\left(\mathrm{Cr}^{3+}\right)$.

\section{METODOLOGIA}

Os materiais utilizados neste trabalho são provenientes de palmeiras nativas da região nordeste do Brasil. Material in natura e casca dos frutos das palmeiras Rabo-de-raposa e Catolé, carvões produzidos pela pirólise do endocarpo do fruto das palmeiras Rabo-de-raposa, Catolé, Ouricuri e o endocarpo do coco foram utilizados. A importância desses frutos está relacionada ao aproveitamento da amêndoa e da polpa utilizada na produção de produtos alimentícios. O endocarpo é a casca mais dura não utilizada desses frutos. Na Tabela 1 são apresentados o código de cada um dos materiais avaliados bem como a descrição do biomaterial e da temperatura de pirólise do biocarvão.

Tabela 1 - Código utilizado para identificação e descrição dos materiais avaliados.

\begin{tabular}{|c|c||c|c|}
\hline Material & Descrição (Planta nativa) & Material & Descrição (Planta nativa) \\
\hline \hline RRIN & Rabo de Raposa - in natura & CT700 & Catolé - carvão pirolisado a $700{ }^{\circ} \mathrm{C}$ \\
\hline RRCAS & Rabo de Raposa - casca & CT400-A & Catolé - carvão a $400{ }^{\circ} \mathrm{C}$, ativado com $\mathrm{H}_{2} \mathrm{SO}_{4}$ \\
\hline RR400 & Rabo de Raposa - carvão pirolisado a $400{ }^{\circ} \mathrm{C}$ & O-400 & Ouricuri - carvão pirolisado a $400{ }^{\circ} \mathrm{C}$ \\
\hline RR500 & Rabo de Raposa - carvão pirolisado a $500{ }^{\circ} \mathrm{C}$ & O-500 & Ouricuri - carvão pirolisado a $500{ }^{\circ} \mathrm{C}$ \\
\hline RR600 & Rabo de Raposa - carvão pirolisado a $600{ }^{\circ} \mathrm{C}$ & O-600 & Ouricuri - carvão pirolisado a $600{ }^{\circ} \mathrm{C}$ \\
\hline RR700 & Rabo de Raposa - carvão pirolisado a $700{ }^{\circ} \mathrm{C}$ & O-700 & Ouricuri - carvão pirolisado a $700{ }^{\circ} \mathrm{C}$ \\
\hline CTIN & Catolé - in natura & O-800 & Ouricuri - carvão pirolisado a $800{ }^{\circ} \mathrm{C}$ \\
\hline CTCAS & Catolé - casca & Coco 500 & Endocarpo de Coco - carvão pirolisado a $500{ }^{\circ} \mathrm{C}$ \\
\hline CT400 & Catolé - carvão pirolisado a $400{ }^{\circ} \mathrm{C}$ & Coco 600 & Endocarpo de Coco - carvão pirolisado a $600{ }^{\circ} \mathrm{C}$ \\
\hline CT500 & Catolé - carvão pirolisado a $500{ }^{\circ} \mathrm{C}$ & Coco 700 & Endocarpo de Coco - carvão pirolisado a $700{ }^{\circ} \mathrm{C}$ \\
\hline CT600 & Catolé - carvão pirolisado a $600{ }^{\circ} \mathrm{C}$ & - & \\
\hline
\end{tabular}


A pirólise dos biocarvões foi realizada em forno tubular Jung (modelo LT6 2010) com taxa de aquecimento de $10^{\circ} \mathrm{C} / \mathrm{min}$ até a temperatura desejada, com tempo de residência de 2 h. O carvão CT400-A depois de pirolisado recebeu um banho de $\mathrm{H}_{2} \mathrm{SO}_{4}$ e posteriormente foi levado a mufla a $750{ }^{\circ} \mathrm{C}$ por $2 \mathrm{~h}$.

\subsection{Avaliação da Afinidade metálica - Adsorção dos íons metálicos}

Essa etapa do estudo teve como objetivo avaliar a afinidade dos biomateriais e carvões pelos metais tóxicos: cobre $\left(\mathrm{Cu}^{2+}\right)$, níquel $\left(\mathrm{Ni}^{2+}\right)$ e cromo trivalente $\left(\mathrm{Cr}^{3+}\right)$. As soluções metálicas monocompostas foram preparadas pela solubilização dos sais $\mathrm{Cu}\left(\mathrm{NO}_{3}\right)_{2} \cdot 3 \mathrm{H}_{2} \mathrm{O}$, $\mathrm{Ni}\left(\mathrm{NO}_{3}\right)_{2} .6 \mathrm{H}_{2} \mathrm{O}$, e $\mathrm{Cr}\left(\mathrm{NO}_{3}\right)_{3} .9 \mathrm{H}_{2} \mathrm{O}$.

Para os testes de afinidade, foram utilizados $0,4 \mathrm{~g}$ de adsorvente seco (em estufa por 24 h) e $40 \mathrm{~mL}$ de solução de monocomposto de cada um dos metais; com concentração de 1 mmol. $\mathrm{L}^{-1}$; foram acondicionados em Erlenmeyers de $125 \mathrm{~mL}$ e agitados $(200 \mathrm{rpm}$ por $24 \mathrm{~h}$ à $25^{\circ} \mathrm{C}$ ) em incubadora orbital (Incubated Saker, SI 600R, Lab Companion Jeio Tech, Korea).

$\mathrm{O}$ pH utilizado nos experimentos de afinidade metálica, de $3,5( \pm 0,5)$ que foi determinado no estudo de especiação metálica pelos programas Hydra/Medusa (para o níquel e cobre) e Visual MINTEQ 3.1 (para o cromo). Para a análise de especiação foram consideradas as razões estequiométricas dos sais de metais utilizados. Uma solução de ácido nítrico $(10 \% \mathrm{v} / \mathrm{v})$ foi adicionada para ajustar o $\mathrm{pH}$, antes e durante o experimento, devido a aumentos no valor do pH. Após 24 horas de agitação, as partículas foram removidas e a solução centrifugada em $4000 \mathrm{rpm}$, por $10 \mathrm{~min}$, de modo a retirar o adsorvente em solução. Nos primeiros testes verificou-se a necessidade de filtrar a solução, após o processo de centrifugação, devido à presença de material fino em solução. Todas as soluções foram filtradas em filtros seringa (MILEX - 0,45 $\mu \mathrm{m}$ ) antes de serem diluídas para a determinação da concentração no espectrofotômetro de absorção atômica (AAS - 7000AA - Shimadzu, Japan), de acordo com as instruções do equipamento. A concentração das soluções antes do processo adsortivo foi também determinada no equipamento de absorção atômica.

A porcentagem de remoção $(\% \mathrm{R})$ foi determinada pela equação 1 , na qual $C_{0}$ : a concentração inicial $\left(\mathrm{mmol} . \mathrm{L}^{-1}\right), C_{e}$ : a concentração de equilíbrio (mmol.L ${ }^{-1}$ ), após $24 \mathrm{~h}$ de adsorção em banho.

$\% R=\frac{\left(C_{0}-C_{\varepsilon}\right)}{C_{0}} \cdot 100 \%$

\subsection{Determinação da Massa específica - Picnometria com gás Hélio}

Para a determinação da massa específica real das biomassas e biocarvões utilizou-se o equipamento Picnômetro Accupyc II 1330 (Gas Pycnometer, marca Micromeritics, USA) à pressão de 2 psia. As análises foram feitas até que o valor obtido se estabilizasse.

\section{RESULTADOS E DISCUSSÕES}

Na Figura 1 os gráficos de especiação metálica em função do pH são apresentados. Os gráficos de especiação (diagramas de equilíbrio) fornecem dados relativos às espécies 
químicas formadas em função do $\mathrm{pH}$ do meio aquoso. Para o níquel, a partir do $\mathrm{pH}$ 6,4, ocorre a formação de hidróxido de níquel na forma de precipitado. Para o cobre, a partir de pH 5,1 ocorre a formação de óxido precipitável e para o cromo as espécies começam a ser formadas em $\mathrm{pH}$ bastante ácido, em torno de 1 . No caso do cromo, as espécies formadas são solúveis até $\mathrm{pH} 4-4,5$, a partir dessa faixa há formação de hidróxido de cromo precipitável. Dessa forma, o pH utilizado nos experimentos de adsorção (afinidade metálica) foi de 3,5, ou ligeiramente inferior a este $\mathrm{pH}$. No $\mathrm{pH}$ de 3,5, há somente espécies solúveis no meio e as reduções observadas das concentrações, após os testes de afinidade, podem ser responsabilizadas apenas ao processo de adsorção e não a precipitação de espécies químicas.

Figura 1 - Especiação metálica em função do $\mathrm{pH}$ para os íons, $\mathrm{Ni}^{2+}, \mathrm{Cu}^{2+} \mathrm{e} \mathrm{Cr}^{3+}$.

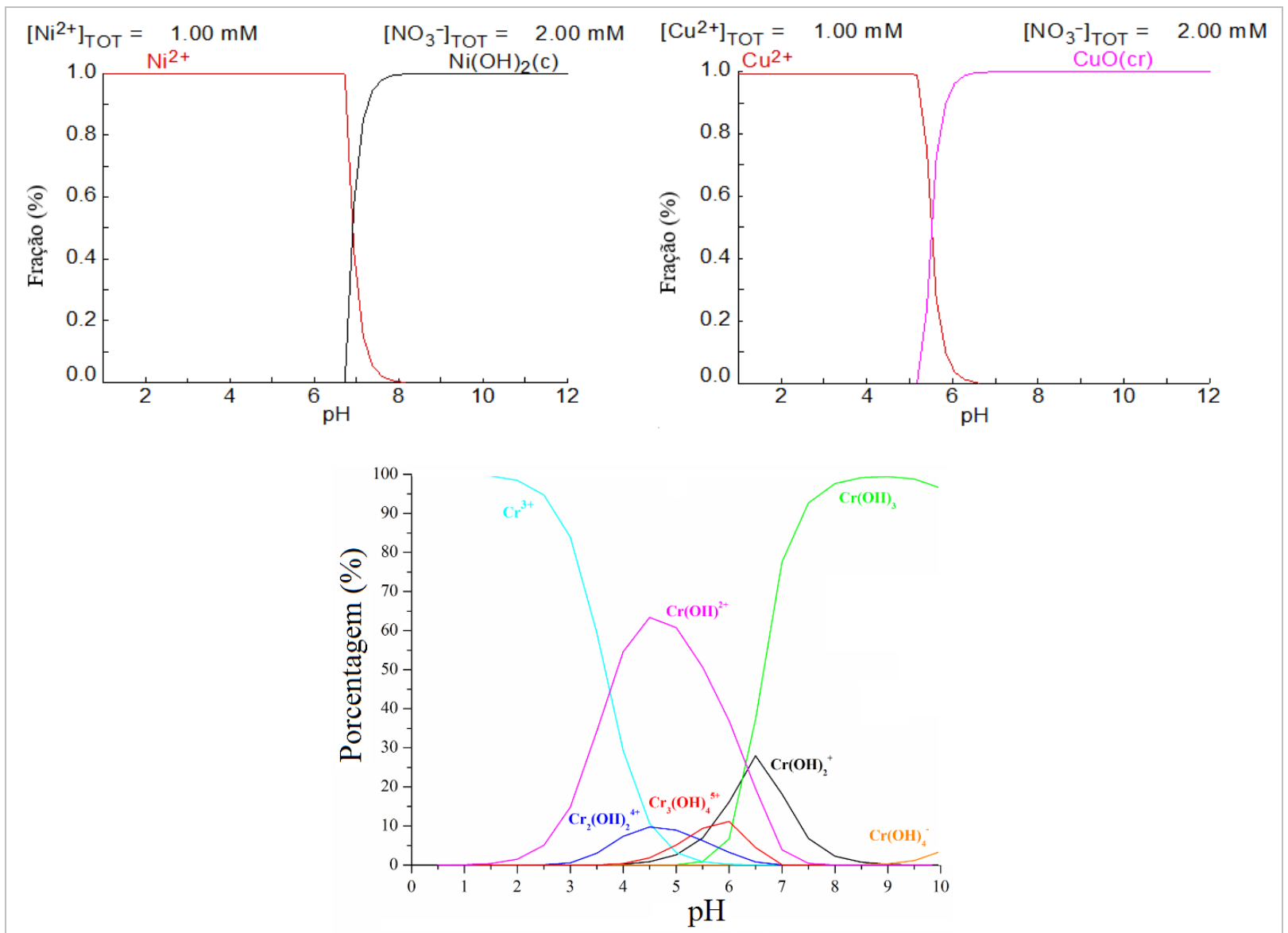

$\mathrm{Na}$ Tabela 2 os valores de massa específica real dos adsorventes e as reduções das concentrações de cobre, níquel e cromo, após o processo de adsorção, são apresentados.

Com exceção da massa específica observada para a casca de Rabo de Raposa (RRCAS) que não é processada, cujo valor foi de $4,1919 \mathrm{~g} / \mathrm{cm}^{3}$, observam-se valores próximos entre os materiais analisados. De maneira geral a pirólise da biomassa promoveu a formação de carvões com massas específicas próximas. Os valores variaram entre 1,3833 a $2,1986 \mathrm{~g} / \mathrm{cm}^{3}$. A semelhança entre as partes utilizadas e as altas temperaturas empregadas para a produção dos carvões podem estar relacionadas com a conformidade entre os valores observados nos adsorventes. 
Tabela 2 - Densidade dos biomateriais e biocarvões e porcentagem de remoção metálica após testes de adsorção (teste de afinidade metálica).

\begin{tabular}{|c|c|c|c|c|}
\hline \multirow{2}{*}{ Material } & \multirow{2}{*}{ Densidade $\left(\mathrm{g} . \mathrm{cm}^{-3}\right)$} & \multicolumn{3}{|c|}{ Redução da concentração dos íons metálicos após adsorção } \\
\hline & & Cobre $(\%)$ & Níquel (\%) & Cromo $(\%)$ \\
\hline RRIN & $1,5870 \quad( \pm 0,0141)$ & 30,2 & 9,6 & 26,1 \\
\hline RRCAS & $4,1919 \quad( \pm 0,0310)$ & 44,6 & 12,7 & 70,3 \\
\hline RR400 & $1,5221 \quad( \pm 0,0016)$ & 12,4 & 2,3 & 22,7 \\
\hline RR500 & $1,5002 \quad( \pm 0,0029)$ & 15,1 & 4,6 & 44,7 \\
\hline RR600 & $1,4237 \quad( \pm 0,0012)$ & 3,8 & 3,9 & 9,2 \\
\hline RR700 & $1,7674( \pm 0,0037)$ & 18,0 & 2,3 & 22,2 \\
\hline CTIN & $1,3833 \quad( \pm 0,0039)$ & 11,4 & 5,8 & 15,0 \\
\hline CTCAS & $1,4127 \quad( \pm 0,0030)$ & 36,2 & 21,3 & 36,0 \\
\hline CT400 & $1,6214( \pm 0,0030)$ & 12,5 & 1,8 & 18,0 \\
\hline CT500 & $1,4587 \quad( \pm 0,0025)$ & 6,0 & 3,1 & 11,9 \\
\hline СТ600 & $1,5217 \quad( \pm 0,0011)$ & 4,1 & 2,7 & 8,0 \\
\hline CT700 & $2,1986( \pm 0,0031)$ & 4,2 & 2,6 & 10,5 \\
\hline CT400-A & $1,8158 \quad( \pm 0,0037)$ & 2,5 & 2,2 & 8,3 \\
\hline $\mathrm{O}-400$ & $1,3992( \pm 0,0011)$ & 2,5 & 3,5 & 6,8 \\
\hline $\mathrm{O}-500$ & $1,4518 \quad( \pm 0,0014)$ & 2,4 & 2,9 & 6,3 \\
\hline O-600 & $1,5292( \pm 0,0033)$ & 2,4 & 2,1 & 5,0 \\
\hline O-700 & $1,5246 \quad( \pm 0,0026)$ & 1,3 & 2,0 & 10,5 \\
\hline $\mathrm{O}-800$ & $1,5573 \quad( \pm 0,0025)$ & 3,3 & 3,8 & 5,4 \\
\hline Coco 500 & $1,4591 \quad( \pm 0,0009)$ & 2,9 & 13,8 & 1,2 \\
\hline Coco 600 & $1,5217 \quad( \pm 0,0018)$ & 0,4 & 2,5 & 9,9 \\
\hline Coco 700 & $1,6426 \quad( \pm 0,0017)$ & 2,3 & 3,1 & 11,0 \\
\hline
\end{tabular}

O material adsorvente proveniente da palmeira Rabo de Raposa apresentou, respectivamente, valores de remoção maiores para o cromo, cobre e níquel. Comparando-se a redução no mesmo metal, os valores observados para o material in natura e casca, que não sofreram tratamento térmico, foram maiores que os observados para os carvões. Possivelmente, o material in natura possui grupos químicos que apresentam afinidade pelos metais avaliados e que podem ter sido degradados na produção do carvão. A maior afinidade observada foi da casca da palmeira pelo cromo, que reduziu em $70,3 \%$ a concentração do metal em solução.

Fenômeno semelhante foi observado nos adsorventes provenientes da palmeira Catolé. Os adsorventes in natura e casca foram capazes de adsorver de maneira mais eficiente os metais em solução, em comparação com os carvões produzidos a partir dessa planta. A casca foi o material que apresentou o maior potencial adsortivo sendo que as reduções observadas foram de 36,2 \%; 21,3\% e 36,0 \% para o cobre, níquel e cromo, respectivamente. Os carvões produzidos a partir de Catolé promoveram reduções das concentrações de metais que variam de $1,8 \%$ a $18,0 \%$. 
As reduções observadas pela adsorção dos metais pelos carvões de Ouricuri variaram entre $1,8 \%$ e $10,5 \%$ e para os carvões de Coco foi de $0,4 \%$ a $13,8 \%$. Com exceção da redução de 10,5 \%, obtida pelo carvão O-700 para o cromo, a média de redução geral foi de apenas 3,6 ( $\pm 1,7) \%$. O carvão produzido a partir do endocarpo de coco promoveu reduções para os metais que variaram de $0,4 \%$ a $13,8 \%$.

Com exceção do CT400-A, os carvões produzidos foram apenas pirolisados, ou carbonizados, não tendo sido submetidos a nenhum processo de ativação físico-química que lhes conferissem um maior potencial adsortivo. Dessa forma, vê-se a necessidade desses materiais serem processados de modo que possam ser criados sítios ativos (ativação do carvão) para que sejam viáveis seus usos em processos de adsorção de íons metálicos. Com relação ao CT400-A, a ativação com $\mathrm{H}_{2} \mathrm{SO}_{4}$, não foi capaz de promover mudanças na superfície do material que permitissem o aumento da capacidade para adsorção.

\section{CONCLUSÃO}

A partir dos diagramas de equilíbrio determinou-se o $\mathrm{pH}$ 3,5 para a realização do experimento. Nesse $\mathrm{pH}$ apenas a adsorção é responsável pela diminuição da concentração do metal durante o experimento. Os valores de massa específica real dos carvões se apresentaram próximos devidos, provavelmente, à semelhança entra as partes dos frutos utilizados na produção do material pirolisado. $O$ processo de adsorção não apresentou resultados satisfatórios, sendo que o material não processado (in natura e casca) apresentou maiores porcentagens de remoção metálica. Os baixos valores de remoção dos íons observados se devem ao fato que as biomassas não foram submetidas a processos de ativações durante a carbonização. A pirólise nesse caso não foi capaz de produzir, por si só, um material adsorvente com potencial adsortivo para metais tóxicos, muito embora novas etapas de estudo sejam necessárias na avaliação desses materiais.

\section{AGRADECIMENTOS}

À CAPES pelo suporte financeiro por meio do programa PROCAD (Edital n ${ }^{\circ}$ 071/2013, $\mathrm{n}^{\circ}$ do projeto: $8881068503 / 2014-1$ ).

\section{REFERENCIAS}

WANG, Y.; HU Y.; ZHAO, X.; WANG, S.; XING, G. Comparisons of Biochar Properties from Wood Material and Crop Residues at Different Temperatures and Residence Time, Energy \& Fuels; v. 27 (10), p. 5890-5899, 2013.

GIORDANO, G. Tratamento e Controle de Efluentes Industriais. Departamento de Engenharia Sanitária e do Meio Ambiente - UERJ, Rio de Janeiro, 2007.

WANG, J; CHEN, C. Biosorption of heavy metals by Saccharomyces cerevisiae: A review, Biotechnology Advances, v. 24, p. 427-451, 2006.

TSAMBA, A. J.; YANG, W.; BLASIAK, W. Pyrolysis characteristics and global kinetics of coconut and cashew nut shells, Fuel Processing Technology, v. 87, p.523-530, 2006.

DEMIRBAS, A. Heavy metal adsorption onto agro-based waste materials: A review, Journal of Hazardous Materials, v. 157, p. 220-229, 2008. 